\title{
La reparación de las víctimas: su confinamiento dentro del marco de la Justicia Transicional ${ }^{* * *}$
}

\section{Victims' reparation: Its confinement inside the Transitional Justice framework}

RESUMEN

El presente artículo expone los hallazgos hechos durante la revisión de la categoría de reparación de las víctimas, estudiada en diferentes áreas del conocimiento. El resultado alcanzado evidencia el confinamiento de esta categoría dentro de los referentes de elaboración conceptual y por los contextos de aplicación de la Justicia Transicional. Debido a ello, surgen algunas controversias, tanto en el plano teórico como en el práctico, las cuales giran en torno a las situaciones en las que ocurrió el daño, a la calidad de víctima y a las circunstancias en las que se exige la reparación. Como alternativa, se expone una estrategia que articula las categorías de víctima y derecho a la reparación, fundamentada en el derecho internacional de los derechos humanos y en la labor de la Corte Interamericana de Derechos Humanos. En consecuencia, se propone la comprensión de la reparación como derecho humano, cuyo desarrollo progresivo promueva su expansión en escenarios no transicionales.

Profesora asociada al Departamento de Jurídicas de la Facultad de Ciencias Jurídicas y Sociales de la Universidad Caldas (Manizales, Colombia). Abogada de la Universidad de Caldas, especialista en Derecho Administrativo de la misma institución, magíster en Derecho de la Universidad de Manizales y doctoranda en Derecho de la Universidad de Medellín. Miembro del Grupo de Investigación de Estudios Jurídicos y Socio-Jurídicos, clasificación A1, en el registro de Colciencias. Contacto: lucero.rios@ucaldas.edu.co ORCID: 0000-0001-7246-8647.

** Recibido el 14 de junio de 2019, aprobado el 12 de junio de 2020.

Para citar el artículo: Ríos TOVAR, L. La reparación de las víctimas: su confinamiento dentro del marco de la Justicia Transicional. En Revista Derecho del Estado, Universidad Externado de Colombia. N. ${ }^{\circ}$ 47, septiembre-diciembre de 2020, 255-285.

DOI: https://doi.org/10.18601/01229893.n47.08

*** El presente texto se basa en el desarrollo de la investigación, llevada a cabo por la autora como doctoranda de la Universidad de Medellín, titulada "El derecho a la reparación de víctimas como garantía de justicia". 
PALABRAS CLAVE

Justicia Transicional, víctima, derechos humanos, derecho internacional de los derechos humanos, responsabilidad internacional.

\section{ABSTRACT}

This paper presents the findings obtained during the review of the victim reparation category, studied in different areas of knowledge. The achieved result evidences the confinement of this category, inside the referents of conceptual elaboration and by the contexts of application of Transitional Justice. Therefore, some controversies arise, both theoretically and practically, which revolve around the situations in which the damage occurred, the quality of the victim and the circumstances in which the repair is required. As an alternative, it presents a strategy that articulates the categories of victim and right to reparation, based on the International Human Rights Law and on the Inter-American Court of Human Rights work. Consequently, the understanding of reparation as a human right is proposed, whose progressive development promotes its expansion in non-transitional scenarios.

\section{KEYWORDS}

Transitional Justice, Victim, Human Rights, International Human Rights Law, International responsibility.

\section{SUMARIO}

Introducción. 1. Enfoques y avances en la investigación sobre la reparación de las víctimas. 3 . El concepto de víctima como determinante para la comprensión del derecho a la reparación. 3. Los fines de la reparación de las víctimas en contextos de Justicia Transicional. 4. Las controversias de la reparación de las víctimas en el campo de estudio de la Justicia Transicional. 4.1. Controversias en el plano teórico. 4.2. Controversias en el plano práctico. 5. Un enfoque desde los derechos humanos para el análisis de la reparación de las víctimas en casos no transicionales. Conclusiones. Referencias.

\section{INTRODUCCIÓN}

Durante las últimas décadas, los investigadores, en diferentes áreas del conocimiento y con distintos enfoques, han estudiado el concepto de reparación, en alusión a las víctimas tanto de graves y sistemáticas violaciones contra los derechos humanos (DDHH) como de infracciones al derecho internacional humanitario (DIH). Estas violaciones han ocurrido durante guerras, dictaduras 
o regímenes represivos. Esta tendencia ha originado un campo de estudio bajo el título de "Justicia Transicional" (JT) ${ }^{1}$, en el cual se encuentra una amplia gama de investigaciones. En ellas se estudia el derecho a la reparación de las víctimas (RV), como uno de los mecanismos idóneos para alcanzar la paz, la reconciliación y la consolidación del Estado social de derecho.

Con base en esas investigaciones, este artículo pretende responder las siguientes preguntas: $1 . ¿$ Cómo incide el concepto de víctima en el desarrollo de la categoría de reparación?, y 2. ¿Cuáles son los fines que se atribuyen a la reparación en contextos de aplicación de la JT? Para responder a estos interrogantes se sintetizan varios estudios sobre la RV, realizadas en distintas áreas del conocimiento a partir de varios enfoques, con el propósito de evidenciar los progresos en cuanto a esta categoría.

Las respuestas a estas preguntas permiten mostrar las controversias que surgen para la RV, relacionadas con su comprensión, interpretación y aplicación como derecho humano, en contextos no transicionales y cuando se la estudia como elemento de la JT. Con ello es posible finalizar este artículo proponiendo un nuevo marco de referencia para la investigación sobre la reparación. Este marco puede contribuir a la reflexión sobre las soluciones a las controversias mencionadas.

Para responder a las dudas planteadas en las anteriores líneas, el presente texto está estructurado de la siguiente manera: primero, se expone cómo la $\mathrm{RV}$ ha sido el centro de diversas investigaciones de carácter interdisciplinario; después, se hace referencia a la categoría de víctima en lo que concierne a su significado iusfilosófico; luego, se toma esta categoría desde la concepción de la JT, para dar paso a las controversias teóricas y prácticas en relación con la reparación; finalmente, se justifica la idea de que la RV, si quiere ser implementada de manera eficaz en contextos no transicionales, debe ser comprendida como un derecho humano.

Por otra parte, la metodología empleada para fundamentar la estructura del presente texto y sus conclusiones es de carácter mixto. En primer lugar, se hace una revisión, por medio de un enfoque deductivo, de textos interdisciplinarios que exponen el sentido y la importancia de la RV. Esta revisión es la base para la subsiguiente comparación conceptual y crítica del contenido expuesto, en relación con la manera como dicha reparación puede ser reconocida en cuanto derecho humano. En segundo lugar, desde un enfoque inductivo, se hace mención de algunos casos, tomados de la jurisprudencia de la Corte Interamericana de Derechos Humanos (Corte IDH) y originados en contextos no transicionales, en los cuales existe un tratamiento integral de la reparación como derecho humano.

1 Turner, C. Deconstructing Transitional Justice. En Law \& Critique. Vol. 24 (2), 2013, 193-209. 
Cabe aclarar que la elaboración del presente artículo se basó en la identificación del estado del arte de la cuestión, realizada sobre la base de artículos e informes de investigación, libros completos y capítulos -como contribución a textos compilatorios o a memorias de foros o encuentros científicos-. Este material abarca un gran número de disciplinas humanas y ciencias sociales: estudios políticos, ciencias políticas, filosofía, ciencias sociales, derecho, criminología, antropología, sociología, historia, psicología y estética. Dicho conjunto de saberes, oportunamente articulado, ofrece una imagen del modo en que la reparación ha trascendido una percepción esquemática y eminentemente normativa.

\section{ENFOQUES Y AVANCES EN LA INVESTIGACIÓN SOBRE LA REPARACIÓN DE LAS VÍCTIMAS}

La existencia de una amplia variedad de investigaciones sobre la $\mathrm{RV}^{2}$ demuestra la importancia de este concepto, no solo en el derecho sino también en distintas áreas del conocimiento, lo cual revela los diversos enfoques con que se ha venido realizando la aproximación a este derecho humano. Estos enfoques son las perspectivas escogidas por los investigadores para estudiar tanto las causas de los daños, que originan el deber de reparar, como los problemas de regulación, interpretación o aplicación de las medidas de reparación.

Como se resalta enseguida, el derecho a la reparación, en la mayoría de las indagaciones académicas, fue analizado como una medida de la $\mathrm{JT}^{3}$. Por lo tanto, los escenarios para el análisis del derecho a la reparación fueron procesos de tránsito ${ }^{4}$ : esfuerzos que partían de situaciones originadas por

2 Vandeginste, S. Reparation. En Bloomfield, D., Barnes T. y Huyse, L. Reconciliation after Violent Conflict. A Handbook. Stockholm: Holmberg \& Holmberg Design AB e International Institute for Democracy and Electoral Assistance - IDEA, 2003, 145: "la reparación se define como una noción comprensiva, la cual incluye otros conceptos similares -como 'restitución', ‘compensación', 'rehabilitación', 'satisfacción' o 'rectificación'-. Dicha noción cubre un amplio catálogo de medidas que son implementadas para corregir cualquier falta ocurrida en el pasado, las cuales pueden o no ser calificadas como delitos o como violaciones a los derechos humanos" (trad. propia).

3 "La JT comprende una variedad de métodos judiciales y no judiciales por medio de los cuales los Estados y los grupos sociales buscan terminar con un pasado de violaciones a los DDHH, proporcionando verdad, justicia, reparación y reconciliación. En algunos casos, esto ocurre en contextos de transición del Estado a la democracia desde un gobierno represivo o hacia la paz desde un conflicto violento. En otros, las democracias establecidas se enfrentan a graves injusticias pasadas: a veces, generaciones después de su comisión. En este último caso, la transición no está en el tipo de régimen; sino en la orientación normativa y el comportamiento del Estado hacia la población violada". STAN, L. y NEDELSKY, N. (eds.). Encyclopedia of Transitional Justice. Vol. 1. New York: Cambridge University Press, 2013, xI; trad. propia.

4 Estos procesos también son enunciados, según el marco de la JT, con la palabra "transicionalidad", la cual nombra el conjunto de todas las acciones y procesos colectivos (sean de carácter institucional, legal, social o cultural) que tienen como propósitos los siguientes: 1 . Influir en un cambio drástico respecto de una previa situación de irregularidad política y jurídica (como 
graves y prolongadas violaciones contra los DDHH, o por infracciones al DIH, con el fin de establecer las condiciones propicias para la construcción de la paz, la reconciliación y la consolidación de la democracia.

Algunas de las investigaciones sobre los abusos del poder estatal exponen argumentos que justifican el deber de reparar a las víctimas: se ha tomado como enfoque la responsabilidad del Estado, para estudiar las injusticias históricas -cometidas contra comunidades aborígenes y poblaciones perseguidas-, con base en los compromisos de la democracia liberal ${ }^{5}$. En otros casos, el examen de los daños, causados por la guerra, las dictaduras militares o la segregación racial, aporta los fundamentos para caracterizar la obligación estatal de reparar a las víctimas, mediante políticas apropiadas para cada caso ${ }^{6}$.

Por otra parte, la perspectiva de políticas públicas ha sido empleada en varias áreas del conocimiento. En la antropología, para analizar el vínculo entre las estrategias de reparación integral y los conceptos de "ciudadanía", "memoria" y "reconocimiento de las víctimas" . En la ciencia política, para evaluar la contribución de la política estatal que promueve los derechos de las víctimas, siendo la reparación evidencia de la deconstrucción de la institucionalidad violenta, a partir de los marcos analítico, jurídico, económico y político: esto ha llevado a explorar las condiciones materiales, causantes de las violaciones contra los DDHH, para lograr entender la reparación integral como un derecho fundamental ${ }^{8}$. En otros casos, la investigación se dirige a determinar el influjo de la reparación en la superación de problemas como

lo son las dictaduras, los conflictos armados y los regímenes autoritarios); 2. Planificar tanto la reconstrucción del Estado de derecho como la reparación del tejido social, y 3. Lograr la paz y la reconciliación duraderas, en un marco de convivencia democrática. Esta definición de la palabra "transicionalidad" está basada, entre otras fuentes, en Bello, M. N., SAlCEdo G., J. C. y Alvarado P., L. L. La reparación administrativa a las víctimas de la violencia en Colombia: análisis del Decreto 1290 del 2008. 2012, 60. [En línea]. Disponible en: http://www.bivipas. unal.edu.co/bitstream/10720/594/1/L-140-PIUPC-2012-460.pdf (Consultado el 30 de octubre de 2018); SALCEdo LóPez, D. M. Género, derecho de las víctimas y Justicia Transicional: retos en Colombia. Granada: Universidad de Granada, 2013, 128; LAPLANTE, L. J. The plural justice aims of reparations. En Buckley-Zistel, S., Koloma Beck, T., Braun, C. y Mieth, F. (ed.), Transitional Justice Theories. New York: Routledge, 2014, 66.

5 Page, J. M. Reparations and State Accountability. Harvard University Press, 2015, 139.

6 Guerrero Andreu, P A. De la responsabilidad del Estado chileno por acciones de gobiernos de facto. Análisis histórico-crítico de las leyes de reparación. Universidad de Chile. 2008, 9. [En línea]. Disponible en: http://repositorio.uchile.cl/tesis/uchile/2008/de-guerrero_p/ html/index-frames.html

; www.cybertesis.uchile.cl/tesis/uchile/2008/de-guerrero_p/pdfAmont/de-guerrero_p.pdf (Consultado el 27 de septiembre de 2018).

7 Ulfe Young, M. E. ¿Y después de la violencia que queda? Víctimas, ciudadanos y reparaciones en el contexto post-CVR en el Perú. Buenos Aires: Consejo Latinoamericano de Ciencias Sociales - CLACSO, 2013, 81.

8 Socha MASSO, N. La reparación integral: los derechos de las víctimas y las obligaciones del Estado. Bogotá: Defensoría del Pueblo y Cooperación Técnica Alemana - GIZ, 2013, 175. 
la discriminación ejercida contra ciertos sectores de la población: la discriminación impide el ejercicio del derecho a la participación de las víctimas, durante el diseño de las políticas públicas de reparación ${ }^{9}$.

Por otro lado, a partir de un enfoque histórico en el área de los estudios políticos, se ha resaltado la importancia de configurar la historia por medio de políticas que promuevan la memoria sobre los conflictos armados, para desentrañar un trasfondo de violencia estructural y poder así trazar la extensión de las medidas de reparación a toda la sociedad ${ }^{10}$. Por su parte, en el campo de la psicología, la investigación se ha enfocado en los daños y sus secuelas psicológicas y psicosociales, los cuales son causados, en los ámbitos individual, familiar, grupal y comunitario, por los actos de violación masiva contra los DDHH. A partir de este enfoque, las investigaciones psicológicas han formulado propuestas de reparación en contextos de represión política ${ }^{11}$.

En el área del derecho, la investigación emplea diferentes enfoques para el análisis del concepto de RV. Algunos estudios sobre derecho internacional (DI) han examinado las fuentes que regulan los derechos de las víctimas a la reparación, la verdad y, en particular, la justicia, para establecer el estatus de tales derechos como ius cogens ${ }^{12}$ o como derecho consuetudinario ${ }^{13}$; así como su aplicación internacional ${ }^{14}$.

En otros casos, la investigación se enfocó en campos jurídicos, como el derecho constitucional, para determinar la contribución que puede tener la reparación de las víctimas en la identidad de los sujetos políticos y en el restablecimiento de la democracia ${ }^{15}$. En el mismo campo del derecho constitucional, en aspectos vinculados con el DI y la sociología del derecho, la investigación fue más específica, al asumir un enfoque diferencial. Este

9 Piper Shafir, I. Obstinaciones de la memoria: la dictadura militar chilena en las tramas del recuerdo. 2006, 189. [En línea]. Disponible en: https://www.tdx.cat/ handle/10803/5444\#page $=1$ (Consultado el 27 de septiembre de 2018).

10 Jelin, E. La lucha por el pasado: cómo construimos la memoria social. Buenos Aires: Siglo xxi Editores, 2017, 156.

11 GómEZ Dupuis, N. Víctimas sobrevivientes de masacres: daño psicosocial y estrategias de reparación. San José de Costa Rica: Instituto Interamericano de Derechos Humanos, 2004, 337.

12 CONTRERAS RamíREZ, J. L. La responsabilidad civil como reparación a las víctimas de graves violaciones a los derechos humanos en el marco de la jurisdicción universal. Getafe: Universidad Carlos III de Madrid, 2015, 128.

13 Evans, C. The Right to Reparation in International Law for Victims of Armed Conflict. London: Cambridge University Press, 2012, 39.

14 Vacas Fernández, F. Los derechos de las víctimas y la negociación: el caso de Colombia. En Díaz-Barrado, C. M., Fernández Liesa, C. R. y Rodríguez-Villasante y Prieto, J. L. Derecho internacional humanitario y derechos humanos. Reflexiones sobre el conflicto colombiano. Pamplona y Cizur Menor: Civitas Thomson Reuters e Instituto Universitario de Estudios Internacionales y Europeos "Francisco de Vitoria", Universidad Carlos III de Madrid, 2013, 541.

15 Delgado Barón, M. Las víctimas como sujetos políticos en el proceso de Justicia y Paz en Colombia: discursos imperantes y disruptivos en torno a la reconciliación, la verdad, la justicia y la reparación. México D.F.: Flacso México, 2011, 36. 
enfoque estuvo basado en criterios para la etno-reparación de las víctimas, mediante la restitución de tierras a favor de pueblos indígenas y comunidades afrodescendientes. Se propuso la categoría de justicia étnica colectiva, con alcance para otras formas de reparación -como la reparación integral, la simbólica o la indemnizatoria- y con base en parámetros orientadores de las medidas de reparación, para víctimas de desplazamiento forzado y despojo de tierras. Estas formas de reparación respetan la identidad cultural de estos pueblos y comunidades, como una forma de impulsar los procesos de transición a la paz ${ }^{16}$.

Otras investigaciones, en el derecho administrativo, analizaron la organización y el funcionamiento de las entidades responsables del diseño, implementación, seguimiento y evaluación de las políticas públicas de $\mathrm{RV}^{17}$.

De otro lado, en el derecho penal se ha investigado sobre la función del derecho y de las instituciones encargadas de evitar la impunidad y reparar a las víctimas de infracciones penales ${ }^{18}$. Igualmente, se ha indagado sobre las limitaciones del proceso penal, para establecer el daño colectivo y garantizar la reparación integral a los sujetos afectados ${ }^{19}$, así como la labor de los órganos judiciales nacionale ${ }^{20} \mathrm{e}$ internacionale $\mathrm{s}^{21}$ que deciden las demandas de reparación de las víctimas.

Otras investigaciones muestran resultados en áreas del conocimiento diferentes de las hasta acá mencionadas. Se destaca, al respecto, la importancia asignada a los contextos de aplicación ${ }^{22}$ de la JT. Tales estudios suelen abordar

16 Garavito Rodríguez, C. y Lam, Y. Etnorreparaciones: la justicia étnica colectiva y la reparación. Oslo: Torkel Opsahl Academic Epublisher y Peace Research Institute Oslo - PRIO, 2012,342 .

17 Bello, M.N., Salcedo G., J.C. y Alvarado P., L. L. La reparación administrativa a las víctimas de la violencia en Colombia: análisis del Decreto 1290 del 2008. 2012, 23. [En línea] Disponible en: http://www.bivipas.unal.edu.co/bitstream/10720/594/1/L-140-PIUPC-2012-460. pdf (Consultado el 30 de octubre de 2018).

18 Aïssaou, K. La victime d'infraction pénale de la réparation à la restauration. Lyon: Université Jean Moulin. Lyon III, 2013, 103.

19 Vallès Muñío, D. Les reparacions econòmiques pels danys derivats de la Guerra Civil Espanyola. Barcelona: Universitat Pompeu Fabra, 2012, 48.

20 GonzÁlez Joves, A. Alcances y limitaciones de la Ley de Justicia y Paz de Colombia (Ley 975 de 2005) como construcción de paz. Granada: Universidad de Granada e Instituto de la Paz y los Conflictos, 2012, 70 .

21 Socha Masso, N. La reparación integral: los derechos de las víctimas y las obligaciones del Estado. Bogotá: Defensoría del Pueblo y Cooperación Técnica Alemana - GIZ, 2013, 145.

22 En este artículo se propone el término "contexto de aplicación" para designar los marcos históricos, sociales y culturales, entre otros, en los cuales tiene realidad una categoría. Desde la perspectiva teórica, el contexto de aplicación constituye la descripción de los escenarios en los que se analiza la funcionalidad de una categoría; por otra parte, desde la perspectiva práctica, su potencial es metodológico: permite evaluar el efecto o la consecuencia derivada de la puesta en lugar y tiempo de una categoría de investigación. Aquí, el contexto de aplicación se emplea para señalar las condiciones de carácter histórico, espacial, social, jurídico, cultural, etc. en que se ha estudiado la reparación de víctimas. 
problemas relacionados, de forma indirecta, con el derecho a la reparación. Por ejemplo: el valor de la verdad judicial y de la verdad que emerge en los procesos de transición, además de su importancia para la configuración de la memoria ${ }^{23}$; o la implementación de instrumentos para la reparación económica y las normas sobre memoria, con fundamento en las diferencias entre esquemas de justicia retributiva y $\mathrm{JT}^{24}$. Asimismo, se han estudiado las características especiales de las medidas de reparación, las cuales se justifican en contextos de aplicación de la $\mathrm{JT}^{25}$; y las relaciones de poder desiguales, que existen entre los géneros desde antes del conflicto armado o dictadura y que se agudizan durante estos, justificándose la aplicación de reparaciones transformadoras ${ }^{26}$.

Estos resultados de investigación evidencian que la RV es una categoría que concita el interés de la comunidad académica, desde diversas áreas del conocimiento y a partir de diferentes enfoques. En efecto, la RV promueve la investigación, por lo menos, en dos grandes líneas: 1. La línea que estudia los problemas relacionados con las situaciones que originan la obligación de reparar (i.e., con carácter retrospectivo) y 2. La línea que analiza los problemas derivados de los procesos tendientes a la regulación, la interpretación y la aplicación del derecho a la reparación (i.e., con carácter prospectivo).

En cuanto a sus desarrollos, las investigaciones aportan argumentos para afirmar que la reparación es un derecho humano, consagrado en instrumentos internacionales, incorporado en muchos sistemas jurídicos nacionales y aplicado por instancias administrativas y judiciales. En igual sentido, los avances permiten señalar que la JT es el enfoque predominante en la investigación sobre reparación: en dicho entorno, ella es considerada un mecanismo cuya naturaleza responde a la aspiración transformadora de las sociedades que tratan de superar un pasado de graves violaciones contra los DDHH y el DIH.

Dicho lo anterior, las características del derecho a la reparación, definidas a partir de su alcance e importancia, están determinadas por el contexto de creación, es decir: el escenario escogido para su análisis durante la investigación. En este escenario, el derecho a la reparación mantiene una relación de interdependencia con la definición y la caracterización del término "víctima", asignado según el marco de la JT. Debido a ello, es necesario revisar

23 Benavides Vanegas, F. S. La verdad, las confesiones judiciales y la memoria del conflicto en el proceso de Justicia Transicional en Colombia. Barcelona: Universitat Pompeu Fabra, 2015, 312.

24 Vallès MuÑío. Les reparacions econòmiques pels danys derivats de la Guerra Civil Espanyola, cit., 14.

25 Juliao Vargas, C. S. Desplazamiento interno, verdad, justicia y reparación en Colombia: la percepción de las integrantes de la Asociación Yo Mujer. Granada: Universidad de Granada, Programa "Paz, Conflictos y Democracia", 2013, 179.

26 LÓPEZ ZWAig, E. S. Reparaciones para mujeres sobrevivientes de violencia sexual durante conflictos armados y dictaduras. Los casos de Argentina y Colombia. Bogotá: Universidad de los Andes, 2016, 49. 
las fuentes jurídicas y las investigaciones que crean esa relación, para lograr un mejor entendimiento de la reparación.

\section{EL CONCEPTO DE VÍCTIMA COMO DETERMINANTE PARA LA COMPRENSIÓN DEL DERECHO A LA REPARACIÓN}

En el DI existen dos perspectivas para la definición del término "víctima"27. La primera perspectiva, correspondiente al derecho penal, considera como "víctimas" a las personas que, individual o colectivamente, han sufrido un daño, como consecuencia de comportamientos que violan la legislación penal o constituyen un abuso de poder ${ }^{28}$. Por otra parte, la segunda perspectiva, surgida del derecho internacional de los derechos humanos (DIDDHH), denomina "víctima" a toda persona que ha sufrido daños, individual o colectivamente, derivados de acciones u omisiones que violen, de forma manifiesta, las normas internacionales de DDHH o infrinjan, de manera grave, el $\mathrm{DIH}^{29}$.

En las dos definiciones, el concepto de víctima está determinado por el daño. Esto se debe a que el daño es un acontecimiento o suceso que causa una alteración. Lo que el derecho cualifica es el efecto de ese estado nuevo de cosas para la víctima, asignándole al efecto mencionado una connotación determinada y teniendo en cuenta el contexto donde se produce dicho daño. En función de la connotación, se toman las decisiones y se podrán adoptar las medidas como garantías al derecho a una reparación integral.

Sin embargo, en ambas definiciones, para asignar la calidad de víctima a una persona o grupo de personas, son determinantes los referentes de elaboración conceptual que aquí se proponen ${ }^{30}$. Dichos referentes son los aconte-

27 Bello, M. N.; Salcedo G., J.C. y Alvarado P., L.L. La reparación administrativa a las víctimas de la violencia en Colombia: análisis del Decreto 1290 del 2008. 2012, 15. [En línea] Disponible en: http://www.bivipas.unal.edu.co/bitstream/10720/594/1/L-140-PIUPC-2012-460. pdf (Consultado el 30 de octubre de 2018).

28 Organización de las Naciones Unidas (onu). Declaración sobre los principios fundamentales de justicia para las víctimas de delitos y del abuso de poder. 1985. [En línea]. Disponible en: https://www.ohchr.org/sp/professionalinterest/pages/victimsofcri meandabuseofpower.aspx (Consultado el 30 de octubre de 2018).

29 ORganización de las Naciones Unidas (ONU). Principios y directrices básicos sobre el derecho de las víctimas de violaciones manifiestas de las normas internacionales de derechos humanos y de violaciones graves del derecho internacional humanitario a interponer recursos y obtener reparaciones. 2005. [En línea]. Disponible: https://www.ohchr.org/sp/professionalinterest/pages/remedyandreparation.aspx (Consultado el 27 de septiembre de 2018).

30 En este artículo se propone el término "referente de elaboración conceptual" para aludir a los acontecimientos, fenómenos, sucesos u otros conceptos, asumidos como base o parámetro para elaborar y estructurar una categoría. Adicionalmente, este término es útil en el plano metodológico, porque permite la identificación de los conceptos comprendidos en una categoría de investigación: en especial, cuando el campo está constituido por muchos resultados de investigación, provenientes de varias áreas del conocimiento. Aquí se emplea para mencionar y diferenciar los distintos conceptos que se adoptan, como referencia para dotar de contenido a la palabra "víctima". 
cimientos que originan los daños que victimizan, puesto que el significado de la expresión "víctima" puede variar dependiendo del enfoque asumido. Así, cuando la regulación jurídica se ubica en el derecho penal, los referentes de elaboración conceptual serán los delitos, el abuso de poder y la impunidad ${ }^{31}$. En cambio, si la disposición jurídica se encuentra en el DI, los referentes de elaboración conceptual serán las situaciones que menoscaben el DIDDHH ${ }^{32}$.

Estas distinciones son relevantes para la interpretación que debe realizar quien diseñe, aplique o evalúe políticas públicas de reparación ${ }^{33}$, o tome decisiones en el ámbito judicial ${ }^{34}$. A partir de los referentes de elaboración conceptual empleados para identificar a las víctimas y reconocerles sus derechos se determinan las normas jurídicas aplicables y, en consecuencia, las medidas de reparación. Por consiguiente, el reconocimiento de la calidad de víctima, en uno u otro evento, es sustancial para efectivizar sus DDHH, así como para garantizarle una reparación individual o colectiva ${ }^{35}$.

En lo concerniente a las investigaciones que adoptan como enfoque el concepto de víctima, acorde con los referentes de elaboración conceptual mencionados, la reparación es estudiada como un elemento de la JT. Estas investigaciones analizan los efectos que tienen, para las víctimas, las respuestas ofrecidas por los sistemas administrativos y las instancias judiciales, para una serie de reparaciones efectivas. Estas respuestas se dan por medio de la legislación, las políticas públicas y la jurisprudencia de órganos nacionales o internacionales ${ }^{36}$.

31 Orentlicher, D., Organización de las Naciones Unidas (onu). Conjunto de principios actualizado para la protección y la promoción de los DDHH mediante la lucha contra la impunidad. 2005. [En línea]. Disponible en: http://www.Derechos.org/nizkor/impu/impuppos.html (Consultado del 30 de octubre de 2018).

32 Otro enfoque para la definición del concepto de víctima, esta vez a partir de la caracterización de la violencia, se puede consultar en BARBUTO, V. et al. Las víctimas y la Justicia Transicional. ¿Están cumpliendo los Estados latinoamericanos con los estándares internacionales? Washington D.C.: Fundación para el Debido Proceso Legal, 2010, 4.

33 Meredith, V. M. Victim Identity and Respect for Human Dignity: A Terminological Analysis. Geneva: Cambridge University Press e International Committee of the Red Cross ICRC, 2009, 259; Moreno, M. C. (ed.). Políticas públicas que hacen justicia: cuatro temas en la agenda de reparación en Colombia. Bogotá: Centro Internacional para la Justicia Transicional y Programa de las Naciones Unidas para el Desarrollo - PNUD, 2011, 51.

34 Guilis, G. La reparación: acto jurídico y simbólico. San José de Costa Rica: Equipo Interdisciplinario del Departamento de Entidades de la Sociedad Civil del Instituto Interamericano de Derechos Humanos, 2004, 299.

35 Sobre la importancia de la perspectiva de las víctimas para la determinación del derecho a la reparación por graves violaciones contra los DDHH en el derecho penal y el derecho internacional, cfr. GómEz IsA, F. Las víctimas y su derecho a la reparación. 2006, 37. [En línea]. Disponible en: http://www.fuhem.es/media/ecosocial/file/revista-papeles/93/arts.\%20 93/V\%C3\%ADctimas_y_Derecho_reparaci\%C3\%B3n_93.pdf. (Consultado el 27 de septiembre de 2018).

36 En este punto se sigue la distinción entre programas de reparación masivos (a cargo de organismos administrativos en los Estados) y decisiones judiciales (las cuales resuelven 
Los resultados de las investigaciones sugieren que el concepto de víctima comprende a la persona, al grupo de personas o a la sociedad en su conjunto cuando hayan sufrido un daño como consecuencia de los hechos que son objeto de la JT. A partir de esta caracterización de las víctimas, las investigaciones examinan y evalúan los efectos de las medidas de reparación, adoptadas en el marco de la JT, tanto en el ámbito administrativo como en el escenario judicial. Los avances en estas investigaciones son relevantes por su nivel prescriptivo, ya que incentivan la búsqueda y formulación de estrategias para:

1) Otorgar participación a las víctimas en el diseño, implementación y evaluación de las reparaciones ${ }^{37}$;

2) Fortalecer las capacidades de agencia de las víctimas, siendo aquellas las libertades suficientes para que las personas obtengan lo que consideran como "valioso" 38 ;

3) Conceder mayor protagonismo a las víctimas en los procesos penales, para garantizar la transparencia de estos y que se abandone un enfoque exclusivamente retributivo -el cual privilegia la punición del victimario, por encima de la necesidad de una reparación integral ${ }^{39}$;

4) Adoptar enfoques diferenciales, en relación con la identidad colectiva, cultural y territorial de las víctimas, para definir e implementar los mecanismos y medidas de reparación adecuados a los contextos de victimización ${ }^{40}$;

demandas de reparación caso por caso, como ocurre en las cortes internacionales y nacionales). Véase De GreIFF, P. (ed.). The Handbook of Reparations. New York: The International Center for Transitional Justice y Oxford University Press, 2010, 451; Organización DE LOS Estados Americanos, Comisión InTERAmericana de Derechos Humanos. Lineamientos principales para una Política Integral de Reparaciones. Washington, D.C.: Secretaría General de la Organización de los Estados Americanos, 2008. [En línea]. Disponible en: http://www.cidh.org/pdf\%20files/ Lineamientos \%20principales\%20para\%20una\%20pol\%C3\%ADtica\%20integral\%20de $\% 20$ reparaciones.pdf (Consultado el 27 de septiembre de 2018).

37 LÓPEZ ZWAIG, E. S. Reparaciones para mujeres sobrevivientes de violencia sexual durante conflictos armados y dictaduras. Los casos de Argentina y Colombia. Bogotá: Universidad de los Andes, 2016, 49.

38 CORREA, C. et al. Reparación integradora para niños, niñas y jóvenes víctimas de reclutamiento ilícito en Colombia. Bogotá: Centro Internacional para la Justicia Internacional, 2014, 29.

39 AïssaOU, K. La victime d'infraction pénale de la réparation à la restauration. Lyon: Université Jean Moulin, Lyon III, 2013, 204; Juliao Vargas, C. S. Desplazamiento interno, verdad, justicia y reparación en Colombia: la percepción de las integrantes de la Asociación Yo Mujer. Granada: Universidad de Granada, Programa "Paz, Conflictos y Democracia”, 2013, 167.

40 GaRavito Rodríguez, C. y LAm, Y. Etnorreparaciones: la justicia étnica colectiva y la reparación. Oslo: Torkel Opsahl Academic Epublisher y Peace Research Institute Oslo - PRIO, 2012, 9; Mendoza Molina, M. Reparación para las víctimas en el Municipio de Tumaco. En Revista Análisis Político. N. ${ }^{\circ}$ 90, 2017, 124; RetTBerg, A. Reparación en Colombia. ¿Qué quieren las víctimas? Bogotá: Deutsche Gesellschaft für Technische Zusammenarbeit (GTZ) GmbH, 
5) Incorporar la perspectiva de género en las políticas públicas para la $\mathrm{RV}^{41}$;

6) Complementar los programas de reparación con medidas de tipo psicosocial y psicológico ${ }^{42}$

7) Fortalecer las medidas de reparación por medio del mejoramiento en el acompañamiento psicosocial y grupal de las víctimas ${ }^{43}$;

8) Complementar los instrumentos para la reparación con elementos simbólicos de contenido educativo ${ }^{44}$

9) Incorporar una dimensión transformadora en las políticas públicas de reparación, en sociedades que ya eran excluyentes y desiguales cuando se cometieron las atrocidades contra sectores marginados o discriminados de la población ${ }^{45}$.

Si bien estos estudios aportan una visión enriquecedora -porque abordan la reparación desde las víctimas con una perspectiva interdisciplinaria-, sus conclusiones están ligadas a un propósito específico: justificar los esfuerzos -realizados por los Estados y la comunidad internacional- para lograr la paz, alcanzar la reconciliación y avanzar en la construcción y en el fortalecimiento de la democracia, como fines de la JT.

\section{LOS FINES DE LA REPARACIÓN DE LAS VÍCTIMAS}

\section{EN CONTEXTOS DE JUSTICIA TRANSICIONAL}

Debido a la asimilación de la JT, como marco de referencia y lugar común de las investigaciones sobre reparación y víctimas, los avances registrados en el conocimiento de estas dos categorías no son generalizables; por el contrario, estos avances dependen de: 1 . Las situaciones en las que ocurrió el daño y 2 . El contexto en que se solicita la reparación. Esto representa un obstáculo para la comprensión, la interpretación y la aplicación de la reparación como un

Embajada de la República de Alemania, Fiscalía General de la Nación y Universidad de los Andes, 2008, 90.

41 Moreno, M. C. (ed.). Políticas públicas que hacen justicia: cuatro temas en la agenda de reparación en Colombia. Bogotá: Centro Internacional para la Justicia Transicional y Programa de las Naciones Unidas para el Desarrollo - PNUD, 2011, 139.

42 GómEz Dupuis, N. Víctimas sobrevivientes de masacres: daño psicosocial y estrategias de reparación. San José de Costa Rica: Instituto Interamericano de Derechos Humanos, 2004, 344.

43 Salcedo López, D. M. Género, derecho de las víctimas y Justicia Transicional: retos en Colombia. Granada: Universidad de Granada, 2013, 144.

44 Theidon, K. Género en transición: sentido común, mujeres y guerra. Bogotá: Instituto de Estudios Políticos y Relaciones Internacionales - IEPRI, Universidad Nacional de Colombia, 2007, 27.

45 Barbuto, V. et al. Las víctimas y la Justicia Transicional. ¿Están cumpliendo los Estados latinoamericanos con los estándares internacionales? Washington, D.C.: Fundación para el Debido Proceso Legal, 2010,6. 
derecho humano: un derecho que tienen todas las personas, sin restricciones temporales o espaciales que supediten su pleno goce y ejercicio ${ }^{46}$.

Para ampliar esta reflexión, valga considerar que las fuentes jurídicas del DIDDHH le otorgan a la reparación el carácter de derecho humano, propio de toda persona que haya sido victimizada ${ }^{47}$. Por lo tanto, es conflictivo, para la esencia de la reparación, condicionar su desarrollo a la concurrencia de un contexto o situación específicos y excluyentes -como los de la JT-.

Con el propósito de conocer las posibles restricciones al derecho a la reparación, las cuales pueden perjudicar a las víctimas, a continuación se hace referencia a los fines que se le atribuyen a aquella categoría cuando se la investiga en el campo de la JT.

Como elemento de la JT, el derecho a la reparación de las víctimas varía en función del contexto histórico específico. Los cambios institucionales y geopolíticos definen y determinan el ser, el alcance y la eficacia del mismo. Dadas estas variaciones históricas, la reparación no es un derecho cuya estructura y fines hayan sido fundamentados de manera definitiva: su existencia y entendimiento han dependido del paradigma vigente de la JT.

En su esclarecedor texto sobre la genealogía de la JT, Ruti Teitel muestra las tres diferentes fases de la teoría sobre JT y sus respectivos objetivos. Durante la primera fase, el propósito central fue "delinear la guerra injusta y demarcar los parámetros de un castigo justificable impuesto por la comunidad internacional". Durante la segunda, además de lo anterior, los objetivos fueron aliviar los daños sufridos por la sociedad e incorporar los valores de un Estado de derecho, a la vez que lograr la reconciliación y la paz. Finalmente, durante el último período, la tendencia expansiva y la normalización de la

46 En el informe presentado ante la Asamblea General de las Naciones Unidas por el Secretario General, en el año de 1969, a propósito del respeto de los DDHH en los conflictos armados, se expuso lo siguiente: "en las disposiciones de la Carta relativas a los DDHH no se distingue entre su aplicación en tiempo de paz y en tiempos de guerra". Adicionalmente, se dijo que la "Declaración Universal de Derechos Humanos no hace en ninguna de sus disposiciones una distinción específica entre tiempos de paz y tiempos de conflicto armado. Establece que los derechos y libertades que proclama corresponden a 'todos' y a 'toda persona', y formula prohibiciones expresando que "nadie' será sometido a actos reprobados por la Declaración". ORganizaCión de LAS NACIONES UNIDAS (2011), p. 109.

47 ORganización de las Naciones Unidas (onu). Declaración sobre los principios fundamentales de justicia para las víctimas de delitos y del abuso de poder. 1985. [En línea]. Disponible en: https://www.ohchr.org/sp/professionalinterest/pages/victimsofcrimeandabuseofpower.aspx. (Consultado el 30 de octubre de 2018). Véase también Organización dE LAS NACIONES UNIDAS (ONU). Principios y directrices básicos sobre el derecho de las víctimas de violaciones manifiestas de las normas internacionales de derechos humanos y de violaciones graves del derecho internacional humanitario a interponer recursos y obtener reparaciones. 2005. [En línea]. Disponible: https://www.ohchr.org/sp/professionalinterest/pages/remedyandreparation.aspx (Consultado el 27 de septiembre de 2018); Orentlicher, D.; Organización de las Naciones Unidas (ONU). Conjunto de principios actualizado para la protección y la promoción de los derechos humanos mediante la lucha contra la impunidad. 2005. [En línea]. Disponible en: http://www.Derechos. org/nizkor/impu/impuppos.html (Consultado del 30 de octubre de 2018). 
teoría sobre JT lograron la fusión entre el derecho de la guerra y el DIDDHH. A partir de esta perspectiva propuesta por Teitel se ve cómo la reparación, su importancia y sus fines, como elementos de la JT, han ido evolucionando con el paso del tiempo. La genealogía de Teitel puede ser empleada como un marco para entender la esencia de la reparación, implícita en las tres fases de la teoría de la $\mathrm{JT}^{48}$.

Así, se puede resumir la evolución de la reparación siguiendo la genealogía de Teitel y comparándola con algunas de las investigaciones, citadas en anteriores secciones, sobre la reparación -en contextos de aplicación de la JT-, de la siguiente manera:

Primera etapa. La RV consistía en la compensación y en la restitución. Ambos procesos plantean la reconstrucción de las condiciones previas al daño padecido, beneficiando a la víctima como consecuencia directa de haber sido objeto de cualquier despojo o perjuicio ${ }^{49}{ }_{-}^{50}$. La víctima es concebida como objeto pasivo de estas medidas, de carácter eminentemente material. Durante esta etapa no se pone en duda el entramado institucional que pudo haber permitido, indirectamente, la producción del daño sobre las víctimas: se prioriza la reconstrucción del Estado de derecho sobre la comprensión de la víctima que ha sido afectada no solamente como sujeto jurídico, sino también como ser humano al que se ha despojado de una serie de libertades que materializan su dignidad ${ }^{51}$. La víctima era menos un ser humano y más un agente económico pasivo ante las decisiones estatales e institucionales de orden monetario, sin que se pusiera en duda las estructuras que pudieron influir en la ocurrencia del daño.

48 Los períodos de las tres fases explicadas por Teitel son: 1. El periodo determinado por los años de entreguerras y de posguerra, respecto a las dos conflagraciones mundiales ocurridas en el siglo xx. Este periodo se comprende entre los años de 1918 y de 1980; 2. El periodo que se inicia a partir de la década de 1980, el cual marca los procesos de democratización política y de modernización, abandonando el orden bipolar mundial establecido durante la Guerra Fría, y 3. El periodo que nace con la creación de la Corte Penal Internacional, por medio del Estatuto de Roma, en el año de 1998. Véase Teitel, R. Transitional Justice Genealogy. En Harvard Human Rights Journal. Vol. 16, 2003, 3, 4, 7-21, 25.

49 RettBerg. Reparación en Colombia, 91. Véase también Balaguer Soriano, A. La semilla sembrada: el potencial transformador de la Justicia Transicional y la restitución de tierras a mujeres en Colombia. Valencia: Universidad de Valencia, 2015, 59.

50 Como profundización de este punto, véanse los capítulos tercero y sexto del completo estudio de Elster, J. Rendición de cuenta: la Justicia Transicional en perspectiva histórica. Buenos Aires: Katz, 186 ss., sobre la JT en retrospectiva. Estos capítulos hacen referencia a la legislación expedida para compensar a las víctimas del régimen nazi -v.gr., la Ley Federal de Restitución, aprobada por el Parlamento de Alemania Occidental en 1956- y a las medidas de compensación y restitución adoptadas por países como Francia, Noruega y Austria, entre otros.

51 Pele, A. La dignidad humana: modelo contemporáneo y modelos tradicionales / A dignidade humana: modelo contemporaneo e modelos tradicionais. 2015. [En línea]. Disponible en https://seer.imed.edu.br/index.php/revistadedireito/rt/printerFriendly/892/944 (Consultado el 27 de septiembre de 2018). 
En otras palabras: se reparaba sin que aún se concibiera: 1. Una percepción multidimensional de la víctima y del daño que trascendiera prioritariamente el ámbito económico -el cual contribuye a la reconstrucción institucional antes que a la recuperación del tejido social- ${ }^{52}$, y 2 . Una reparación que significara una ulterior crítica de las formas sistémicas de la violencia, en contextos no transicionales, dado que dicha violencia es producto de un orden cultural y social en el cual existe y se respeta el Estado de derecho ${ }^{53}$.

Segunda etapa. La víctima pasa de ser percibida como un destinatario pasivo de todas las medidas gubernamentales, a ser participante, observador y crítico de cualquier propuesta de reparación. Lo anterior señala que a los fines de la compensación y la restitución, presentes en la primera etapa, se agregan la reconciliación, la paz $^{54}$ y la construcción de sociedades democráticas más inclusivas y menos discriminatorias ${ }^{55}$-mediante el reconocimiento de las víctimas como actores políticos ${ }^{56}$ que participan en la configuración de acciones institucionales, con el fin de evitar la repetición de los hechos victimizantes ${ }^{57}-$. Esto exige una serie de cambios que van más allá de las circunstancias directas que tuvieron como consecuencia el daño y el menoscabo de los DDHH. La reparación, además de ser material, busca emplear medidas simbólicas y garantías de no repetición, para evitar que una afectación masiva de derechos vuelva a ocurrir. Este ambiente contribuyó a que se formularan concepciones como el ya mencionado enfoque diferencial, relacionado con el contexto social y cultural de las víctimas, como componente necesario para una reparación Integral ${ }^{58}$.

Tercera etapa. La RV se consolidó por medio de una consistente fundamentación del derecho humanitario. Esto se dio con el fin de legitimar, racional y razonablemente, los procedimientos para la desmovilización de grupos al margen de la

52 Van Boven, T. Estudio relativo al derecho a la restitución, indemnización y rehabilitación a las víctimas de violaciones flagrantes de los derechos humanos y las libertades fundamentales. 1993. [En línea]. Disponible en: http://www.derechos.org/nizkor/espana/doc/ boven.html

53 ŽıžEK, S. Sobre la violencia: seis reflexiones marginales. Barcelona, Paidós, 2009, 65.

54 González González, D. Y., Amaya Barrera, N. G. y Cárdenas Ortiz, F. Justicia restaurativa frente a la Ley de Justicia y Paz y la Ley de Víctimas en Colombia. Bogotá: Universidad Libre, 2012, 11.

55 FRIEs, L. (coord.). Sin tregua. Políticas de reparación para mujeres víctimas de violencia sexual durante dictaduras y conflictos. Santiago de Chile: Corporación Humanas y Centro Regional de Derechos Humanos y Justicia de Género, 2008, 28.

56 RetTBerg. Reparación en Colombia, cit., 96.

57 Hazan, P. Measuring the Impact of Punishment and Forgiveness: A Framework for Evaluating Transitional Justice. Geneva: Cambridge University Press e International Committee of the Red Cross - ICRC, 2006, 42.

58 GaRAVITO RodríGUEZ, C. y LAm, Y. Etnorreparaciones: la justicia étnica colectiva y la reparación. Oslo: Torkel Opsahl Academic Epublisher y Peace Research Institute Oslo - PRIO, $2012,18$. 
ley ${ }^{59}$-cuyos resultados, de acuerdo con algunas investigaciones, son dudosos ${ }^{60}-$. Lo anterior implicó que la esfera de la reparación no fuera exclusiva de las víctimas directas. La necesidad de integrar a miembros vulnerables de la sociedad, con el fin de fortalecer el Estado de derecho, supuso incorporar elementos que originariamente estaban en la marginalidad y que intervinieron en la victimización y menoscabo de los DDHH. La desmovilización de miembros de grupos ilegales y alzados en armas exige, para su éxito, medidas de reinserción y reintegración: esto supone el reconocimiento de derechos civiles, sociales, económicos y culturales de quienes se vieron forzados a actuar según una lógica guerrerista y conflictiva que socavaba la legitimidad estatal. La reparación se revela desde un punto de vista integral, dentro de un proceso que reúne diversos esfuerzos para la reconstrucción del tejido social, jurídico e institucional de una nación; se busca, por extensión, la reconciliación entre víctimas y victimarios como superación de un pasado traumático.

Asimismo, Teitel advierte sobre cómo la JT puede, de manera indirecta, silenciar cualquier crítica, por medio del uso de su vocabulario, para enunciar y describir procesos de reparación: "Es difícil resistir la normalización de la JT. Hay una significativa pérdida en el vocabulario desde el cual hacer cualquier crítica [...] Sólo el tiempo dirá si acaso y hasta qué punto estos acontecimientos presentarán un serio desafío al Estado de derecho, o si están asociados con el presente ciclo de política contemporánea" ${ }^{61}$.

Tras este breve estudio comparado de las investigaciones sobre reparación, comprendidas desde la genealogía de Teitel, se hace evidente la omnipresencia de la JT como marco conceptual: desde la compensación y restitución, pasando por la participación de las víctimas, hasta las medidas de reinserción y reintegración. Todas estas acciones tienen en común la transicionalidad, entendida como una etapa intermedia entre la crisis y la normalización estatal, entre la anomalía y el dominio del Estado de derecho; por consiguiente, no hay una continuidad de la reparación como derecho permanente de las víctimas, sin importar si existe o no una transicionalidad.

A partir de lo mencionado en la presente sección, se debe demostrar que los fines atribuidos a la RV condicionan su conocimiento, interpretación y aplicación como derecho humano a un contexto específico. Esto puede ser atribuido, como se sugirió en las líneas anteriores, a la reducción de la reparación como un elemento dentro de la JT. Este condicionamiento de la

59 Quinche Ramírez, M. F. Los estándares de la Corte Interamericana y la Ley de Justicia y Paz. Bogotá: Universidad del Rosario, 2009, 121.

60 Centro Internacional de Toledo Para la PAZ - CitPax. 2010. Tercer Informe del Observatorio Internacional para el Desarme, la Desmovilización y la Reintegración (DDR) según el marco jurídico de la Ley de Justicia y Paz. 2010. [En línea]. 145. Disponible en: http://www. toledopax.org/sites/default/files/Tercer_Informe_CITpax_Observatorio_DDR_Ley_Justicia_Paz_ septiembre_2010.pdf (Consultado el 27 de septiembre de 2018).

61 Teitel. Transitional Justice Genealogy, cit., 25; trad. propia. 
reparación plantea una serie de controversias, las cuales dan paso a discusiones sobre su eficacia como categoría jurídica -i.e., la reparación y su importancia para la promoción y la garantía de los DDHH-.

\section{LAS CONTROVERSIAS DE LA REPARACIÓN DE LAS VÍCTIMAS EN EL CAMPO DE ESTUDIO DE LA JUSTICIA TRANSICIONAL}

El derecho a la RV, en las investigaciones citadas, se ha estudiado como elemento de la JT, junto con los derechos a la verdad y a la justicia. En este contexto surgen problemas de carácter teórico y práctico que significan controversias para la comprensión, la interpretación y la aplicación del derecho a la RV.

\subsection{Controversias en el plano teórico}

En el plano teórico, en el cual se busca una comprensión conceptual y se ensayan interpretaciones de carácter amplio y necesario, la principal controversia que enfrenta la RV es la exigencia que se le plantea de justificar, de manera sólida, la responsabilidad del Estado por las injusticias y las violaciones contra los DDHH, cometidas durante regímenes autoritarios o conflictos armados. Sin embargo, no debe olvidarse que el vínculo entre la responsabilidad del Estado y los DDHH, para comprender la importancia del derecho a la reparación, siempre ha estado contextualizado en casos donde la transicionalidad ha sido un concepto ineludible ${ }^{62}$.

Esta visión de la reparación, vinculada necesariamente con la JT, continúa con las dificultades señaladas previamente respecto de la genealogía de Teitel: la transicionalidad se convierte en un lenguaje que limita la formulación del derecho a la reparación y su posible aporte en situaciones donde el Estado de derecho no ha sido vulnerado ni por guerras ni por dictaduras. Se observa un grave déficit en las investigaciones, al no poderse trasladar la responsabilidad del Estado, por graves violaciones contra los DDHH, hacia contextos no transicionales. Lo anterior lleva a formular la siguiente pregunta: $¿$ se encuentra el Estado, como garante del derecho y de la paz, lo suficientemente comprometido con los DDHH, hasta el punto de autocontenerse y nunca atentar contra ellos?

Se pone en duda, por consiguiente, la perspectiva de que las acciones estatales generen víctimas únicamente en contextos transicionales. Esta idea

62 GuerRero ANDREu. De la responsabilidad del Estado chileno por acciones de gobiernos de facto, cit., 10. Véase también Gómez SÁnchez, G. S. Justicia Transicional "desde abajo": un marco teórico constructivista crítico para el análisis de la experiencia colombiana. 2013, 139. [En línea]. Disponible en: http://bibliotecadigital.udea.edu.co/bitstream/10495/3142/1/ GomezGabriel_Justiciatransicionaldesdeabajo.pdf (Consultado el 30 de octubre de 2018). 
se hace más clara cuando se explora la controversia enfocada en la relevancia de la víctima como eje central de la reparación ${ }^{63}$.

Según esta controversia teórica, se descarta la relevancia absoluta del victimario desde una visión clásica y que ha estado vinculada, tradicionalmente, con el derecho penal. En contraste, al darle una relevancia esencial a la figura de la víctima sobre el victimario, se ha empleado implícitamente el marco de los DDHH. La víctima, como núcleo del derecho a la reparación, empieza a convertirse, gracias a la visión deontológica que surge de la jurisprudencia internacional de los $\mathrm{DDHH}^{64}$, en un concepto que no se reduce a la transicionalidad ni a una aplicación del derecho, como respuestas a una serie de situaciones anómalas de carácter institucional. De lo anterior se deduce la prelación de la victimización, como consecuencia de un daño, sin que importe el contexto histórico previo: no importa si la víctima lo es a causa de un conflicto internacional, de una guerra civil, de un accionar ilegal del Estado, según un gobierno de facto o durante el establecimiento de un régimen autoritario. Inclusive, no importa si el daño se dio dentro de las funciones regulares del Estado.

Desde la perspectiva más amplia de los DDHH, la visión de la transicionalidad le da todavía relevancia al victimario sobre la víctima. Al abandonarse paulatinamente el marco de la JT se observa que lo realmente importante es la obligación estatal de reparar, sin importar las causas históricas o circunstanciales del daño. Se considera, de manera prioritaria, el grado de daño padecido y cuáles deben ser las medidas relevantes para el resarcimiento individual y colectivo.

Estas controversias, relacionadas con la importancia de la víctima desde la perspectiva de los DDHH, adquieren relevancia para la construcción de un nuevo enfoque, el cual es expuesto en la sección 5 del presente texto.

63 Contreras Ramírez, J. L. La responsabilidad civil como reparación a las víctimas de graves violaciones a los derechos humanos en el marco de la jurisdicción universal. Getafe: Universidad Carlos III de Madrid, 2015, 125.

64 La jurisprudencia de la Corte IDH, como fuente del DIDDHH, aporta no solamente casos, sino también argumentos a partir de los cuales se puede delinear una visión deontológica del derecho a la reparación en contextos no transicionales. El trabajo de los investigadores es, por consiguiente, descubrir la potencia jurídica de las posibles delineaciones, para configurar dicha dimensión deontológica. Algunos elementos que aportan a la configuración y definición de esta dimensión están presentes en GARCíA RAMíREZ, S. Raíz, actualidad y perspectivas de la jurisdicción interamericana de derechos humanos. México: Cuestiones Constitucionales, 2009, 156; Calderón Gamboa, J. F. La evolución de la "reparación integral" en la jurisprudencia de la Corte Interamericana de Derechos Humanos. México: Comisión Nacional de los Derechos Humanos, 2013, 42; Rollim PeiXoto, A. La evolución del sistema de reparación a las víctimas de tortura en el ámbito de la Corte Interamericana de Derechos Humanos. Salamanca: Universidad de Salamanca, 2015, 225. 


\subsection{Controversias en el plano práctico}

En primer lugar, el vínculo entre reconciliación y democratización, en sociedades en proceso de posconflicto, plantea, para el derecho a la reparación, el desafío de trascender la esfera de las víctimas. Teniendo en cuenta lo dicho, las investigaciones proponen soluciones a las causas del conflicto, o de los regímenes de facto, como parte del compromiso democrático. De lo anterior se deduce que el Estado, los políticos y la población en general, por medio de fuertes vínculos, deben ser los encargados de la implementación de respuestas que propicien la reconciliación. Estos vínculos deben llevar a la democratización, como dimensión que necesita del derecho a la reparación para un cambio profundo en las instituciones -cambio que incluya tanto un control constante sobre el poder como un fortalecimiento de la rama judicial- más allá de la eliminación de todo legado autoritario ${ }^{65}$.

En segundo lugar, dentro de los contextos transicionales marcados por la desigualdad, las condiciones de pobreza y una situación social inequitativa -ante una institucionalidad débil-, la RV queda igualmente sujeta a las tensiones entre justicia distributiva y correctiva. En este escenario se develan las potenciales limitaciones del enfoque de la JT: sin una mayor participación y empoderamiento de las víctimas durante los procesos de reparación, no pueden implementarse las medidas requeridas para un pronto fortalecimiento de las comunidades. Es por ello que se propone, como solución teórica, el concepto de reparaciones transformadoras que propicien la justicia distributiva y la participación de las víctimas ${ }^{66}$. En otras palabras: se requiere de la intervención de las víctimas, teniendo en cuenta el grado de las atrocidades padecidas y las realidades a las que se tienen que enfrentar para poder conservar y defender sus derechos. Lo anterior supone una articulación de los derechos civiles y políticos con los derechos sociales, económicos y culturales. Tales derechos deben ser protegidos por medio de herramientas normativas que no se reduzcan a reconocer una dimensión jurídica que obvie las realidades de las periferias, lejanas a las circunstancias de los centros legislativos e institucionales. En este acercamiento a las periferias es donde cobra importancia el afianzamiento mutuo de las concepciones de justicia distributiva y correctiva.

65 Pacheco Oreamuno, G., Acevedo Narea, L. y Galli, G. Verdad, justicia y reparación. Desafios para la democracia y la convivencia social. San José de Costa Rica: Instituto Internacional para la Democracia y la Asistencia Electoral, Instituto Interamericano para los Derechos Humanos y Agencia Sueca de Cooperación Internacional para el Desarrollo, 2005, 41.

66 UPRIMNY YePES, R. y GUZMÁn RodRíGUEz, D. E. En búsqueda de un concepto transformador y participativo para las reparaciones en contextos transicionales. 2010, 271. [En línea]. Disponible en: http://www.deJusticia.org/files/r2_actividades_recursos/fi_name_recurso.679.pdf (Consultado el 27 de septiembre de 2018); Benavides Vanegas, F. S. ¿Tiene futuro la Justicia Transicional? En Revista Internacional Derecho Penal Colombiano. N. ${ }^{\circ}$ 58, 2017, 25. 
Esta discusión sobre el modelo de justicia, en referencia a la RV, también se presenta al confrontar la justicia correctiva con la justicia social. Tomando como marco una teoría liberal de la justicia, las investigaciones sugieren que a más fuerza destructiva de la guerra, menos potencia tendrá el derecho a la reparación. Por consiguiente, deberá otorgarse un mayor énfasis a las políticas encaminadas a garantizar los derechos básicos de toda la sociedad. Se requiere la presencia de un sistema legal funcional que haga operativos los principios del Estado social de derecho ${ }^{67}$. Esta visión, que aúna justicia correctiva y justicia social, se basa en la reconstrucción y la continuación de los diversos proyectos de vida. El Estado, por consiguiente, debe reparar y proteger la autonomía individual, ejerciendo su potestad para que los victimarios puedan financiar el restablecimiento completo, rápido y seguro de los planes y proyectos perjudicados por el daño ocasionado. Puede concluirse que el vínculo entre justicia social y correctiva, por medio de la teoría liberal de la justicia, convierte a la reparación en una noción abierta que no puede ni debe enclaustrarse dentro del marco de la JT.

Sin embargo, a pesar de la visión liberal, en el plano práctico o de aplicación de las medidas de RV se revelan problemas de implementación y obstáculos para el cumplimiento de las obligaciones internacionales sobre DDHH por parte del Estado ${ }^{68}$. Igualmente, se cuestionan las condiciones que debe satisfacer una reparación en casos de masivos y sistemáticos abusos contra los $\mathrm{DDHH}^{69}$. Esta última finalidad de la reparación se vincula con otro de los desafíos que suponen las investigaciones sobre este derecho, en contextos de aplicación de la JT.

En esos casos, la reparación se interpreta, además, como un principio de DIDDHH que sustenta la lucha contra la impunidad ${ }^{70}$. En tal escenario, la reparación por violaciones masivas contra los DDHH, al debatirse entre el cumplimiento de compromisos internacionales y la parcial o total impunidad, queda comprometida por los cambios políticos y administrativos de carácter institucional. Dichos cambios pueden excluir este derecho de la esfera de las víctimas y trasladarlo hacia el ámbito estatal. La exclusión, como riesgo de que la impunidad derive en revictimización, se convierte en un desafío, para

67 Kalmanovitz, P. Justicia correctiva vs. Justicia social en casos de conflicto armado. 2010, 81. [En línea]. Disponible en: https://revistas.urosario.edu.co/index.php/sociojuridicos/ article/view/1366 (Consultado el 27 de septiembre de 2018).

68 Guillerot, J. y Magarell, L. Reparaciones en la transición peruana. Memorias de un proceso inacabado. New York: Asociación Pro Derechos Humanos - APRODEH, International Center for Transitional Justice - ICTJ y OXFAM, 2006, 167.

69 De Greiff, P. (ed.). The Handbook of Reparations. New York: The International Center for Transitional Justice y Oxford University Press, 2010, 451.

70 Organización de las Naciones Unidas (onu), Alto Comisionado para los Derechos Humanos. Justicia Transicional y derechos económicos, sociales y culturales. 2014, 27. [En línea]. Disponible en: http://www.ohchr.org/Documents/Publications/HR-PUB-13-05_sp.pdf (Consultado el 27 de septiembre de 2018). 
que la autonomía individual, la participación de las comunidades victimizadas y el empoderamiento democrático se hagan presentes en un constante fortalecimiento del derecho a la reparación. Por lo tanto, un reconocimiento de la actividad y del punto de vista de las víctimas se hace necesario para una mayor ductilidad de la reparación, en contextos que no sean transicionales (relacionados con la violencia sistémica y estructural de la sociedad) $)^{71}$.

Otro desafío importante para la RV, en el nivel práctico, es la efectividad de los mecanismos de JT-tales como las comisiones de la verdad y los tribunales creados para establecer la verdad histórica y judicial-. Si las comisiones de la verdad están orientadas a esclarecer los hechos atroces, los tribunales, por su parte, se encargan de los procesos judiciales cuyo objetivo es declarar la responsabilidad de los autores de las violaciones contra los DDHH y de las infracciones al DIH. En estas circunstancias, el derecho a la reparación de las víctimas puede quedar insatisfecho o, en el mejor de los casos, ocupar un lugar secundario en las agendas estatales. Tanto las comisiones como los tribunales deben servir, en consecuencia, como instituciones que protejan la dimensión jurídica del Estado social de derecho, más allá de cualquier circunstancia que determine una transicionalidad. Ambas instancias se convierten en espacios indispensables para una apertura de la reparación, sin que ella se agote en una visión de la transicionalidad, donde puede asumirse, equivocadamente, que la ausencia de conflicto o el final de una anormalidad estatal son suficientes para cohesionar una sociedad que ha padecido un daño masivo ${ }^{72}$.

En resumen: de las investigaciones relevantes, ya sea en el plano práctico o teórico, se deduce la necesidad de examinar permanentemente los compromisos que asume un Estado con las víctimas. Estos compromisos estatales deben basarse en la garantía de los derechos que consagran el DiDDHH y el DIH, yendo más allá de los logros de la JT -como pactar acuerdos con grupos ilegales o resolver problemas relacionados con el deber de implementación de las políticas de paz- ${ }^{73}$.

Hasta aquí, la intención de este artículo ha sido mostrar los desarrollos investigativos sobre el derecho a la reparación, en varias áreas del conocimiento y desde diversos enfoques. Igualmente, se ha pretendido demostrar el vínculo de esta categoría con el concepto de víctima. Finalmente, se han destacado los desafíos a los que se enfrentan este derecho y el avance en su

71 Žı̌̌EK, S. Sobre la violencia: seis reflexiones marginales. Barcelona, Paidós, 145.

72 MANI, R. La reparación como un componente de la Justicia Transicional: la búsqueda de la "justicia reparadora" en el posconflicto. En Minow, M., CROCKER, D. A. y MANI, R. (coord.), Justicia Transicional. Bogotá: Siglo del Hombre Editores, Pontificia Universidad Javeriana Instituto Pensar y Universidad de los Andes, 2011, 43.

73 CAMILLERI, M. Justicia y paz en Colombia: el derecho a la verdad, la justicia y la reparación. Análisis de la Ley 975 y Decreto 4760 de 2005 según estándares internacionales de protección de los derechos humanos. San José de Costa Rica: Centro por la Justicia y el Derecho Internacional - Cejil, 2006, 20. 
conocimiento, cuando a aquel se le restringe o limita a un contexto específico que lo ubica como un elemento enclaustrado dentro del marco de la JT.

Con fundamento en lo expuesto, se propone un marco para la investigación de la RV, justificado por algunas sentencias de la Corte IDH, consistente en una comprensión más amplia de su naturaleza como derecho, fortalecido por su principal fuente jurídica: el DIDDHH.

\section{UN ENFOQUE DESDE LOS DERECHOS HUMANOS PARA EL ANÁLISIS DE \\ LA REPARACIÓN DE LAS VÍCTIMAS EN CASOS NO TRANSICIONALES}

Como lo demuestran algunas de las investigaciones y de las fuentes jurídicas del DI consultadas, la reparación es una categoría de doble faz: se trata tanto de un deber de los Estados como de un derecho de toda persona ${ }^{74}$. Siendo así, los esfuerzos por mejorar su comprensión, interpretación y aplicación se orientan a la expansión de los limitados contornos que le fija el concepto de víctima ${ }^{75}$ dentro del marco de la JT. En otras palabras: se aspira a cambiar el entendimiento del concepto de víctima y del derecho a las reparación, desde una concepción de justicia no transicional.

Una de las particularidades del derecho a la reparación es que comprende o engloba otros derechos que han sido afectados por un comportamiento con efectos en los bienes jurídicos de una persona, grupo de personas, comunidad o sociedad como un todo. Por lo tanto, según una visión contemporánea, sería preciso orientar las posteriores investigaciones hacia la demostración de cómo la promoción y la garantía de la RV contribuye a la defensa de la dignidad humana ${ }^{76}$. Por consiguiente, la evolución de los conceptos de víctima y de dignidad humana, los cuales reflejan una serie de cambios institucionales e históricos, es una dimensión imprescindible para la apertura y el fortalecimiento del derecho a la reparación en situaciones no transicionales.

74 TeItel, R. Transitional Justice Genealogy, cit., 21; Socha Masso, N. La reparación integral: los derechos de las víctimas y las obligaciones del Estado. Bogotá: Defensoría del Pueblo y Cooperación Técnica Alemana - GIZ, 2013, 19.

75 Este concepto está ligado a graves violaciones a los DDHH e infracciones al DIH en conflictos armados, dictaduras y regímenes autoritarios.

76 La dignidad, como un estatus que guía el sentido del derecho, es semejante al ejercicio de un cargo, al posicionamiento de una persona respecto del resto de la sociedad, como una presencia que se hace viva en la construcción de la realidad social. La dignidad, así establecida, busca ser incluyente y universalizable en relación con: 1. El goce y la defensa de los DDHH y 2. La condición humana como base para que cada individuo sea libre de desarrollar un proyecto de vida determinado. La dignidad resulta siendo el puente entre los DDHH como aspiración colectiva y el reconocimiento del individuo por parte del Estado. Estas afirmaciones se deducen de la lectura de Pele. La dignidad humana, cit.; Meredith. Victim Identity and Respect for Human Dignity, cit., 264; WALDRON, J. J. Is Dignity the Foundation of Human Rights? 2013. [En línea]. Disponible en: https://www.peacepalacelibrary.nl/ebooks/files/36335655X.pdf (Consultado el 27 de septiembre de 2018). 
Para aplicar el enfoque sugerido, incorporando los conceptos de dignidad y de víctima para un fortalecimiento del derecho a la reparación, se plantea una estrategia en tres pasos, la cual está implícita en las páginas anteriores: 1. Determinar el contenido y las características esenciales del derecho a la $\mathrm{RV}$, en los contextos de aplicación exclusiva de la JT; 2. Elaborar argumentos basados en la teoría de los DDHH, que hagan posible la apropiación de los desarrollos, tanto teóricos como prácticos, de las investigaciones, así como de los avances del DI en materia de JT, y 3. Develar un nuevo contenido iusfilosófico del derecho a la RV, sustentado en su contribución a la dignidad humana. Este tercer paso tendrá un doble efecto, tanto teórico como metodológico: teórico, porque se orienta a elaborar un concepto sobre el derecho a la reparación (concepto que revele su contribución a la dignidad humana); metodológico, porque articula los conceptos de víctima, dignidad humana y derecho a la reparación. A partir de estos tres puntos debe justificarse la expansión de la categoría de RV, dado su carácter de derecho humano.

La perspectiva de los DDHH, que orienta la estrategia enunciada en las anteriores líneas, tiende un puente entre una serie de principios que buscan proteger, de manera permanente, a la dignidad humana, a partir de un reconocimiento de quién y cómo puede ser reparada la víctima. Por lo tanto, no se puede prescindir del discurso de los DDHH si se busca una apertura del derecho a la reparación para casos que no presupongan la JT. Gracias al mencionado discurso, visiones que buscan universalizarse y tender puentes entre la justicia social y la reconciliación nacional, como la teoría liberal, tienen un lugar para justificar la defensa de la dignidad humana y, por extensión, la importancia perenne del derecho a la reparación ${ }^{77}$.

Sin embargo, se hace la observación de que el discurso de los DDHH, asumido desde la teoría liberal, adolece de una gran dificultad derivada del hecho de no haber desarrollado toda su fuerza jurídica y concreta en favor de las personas más vulnerables ante el Estado. La teoría liberal se ajusta bien al marco conceptual de la JT: ambos buscan responder a una serie de crisis sociales, institucionales y colectivas, con el fin de reconstruir una sociedad desgarrada por la violencia y los abusos del Estado. No obstante, el discurso coyuntural no ha servido de plataforma para que los DDHH sean vistos como un acuerdo permanente, una vez que el Estado haya recuperado una posición dominante como garante del derecho y de la sociedad civil. El derecho a la reparación, al ser leído desde la posibilidad de ser integrado a los demás DDHH (gracias a que la calidad de víctima no está ligada necesariamente a un contexto de transicionalidad), pone en duda una visión mínima de la intervención estatal.

77 Olásolo Alonso, H. Dignidad humana, derecho internacional penal y Justicia Transicional.2014. [En línea]. Disponible en: https://revistas.urosario.edu.co/index.php/sociojuridicos/ article/view/3218 (Consultado el 27 de septiembre de 2018). 
Para finalizar, se enuncia cómo la jurisprudencia de la Corte IDH resulta pertinente para señalar la necesidad de reconocer el derecho a la reparación como derecho humano en todo tipo de contextos. En efecto, la Corte IDH ha resuelto casos, surgidos de un marco fáctico no transicional ${ }^{78}$, relacionados con hechos de censura, violación a los derechos políticos, destitución de funcionario judicial, violación a los derechos políticos, condena a pena de muerte, detención arbitraria, adopción no consentida, prohibición de practicar la fecundación in vitro y expulsión de nacionales extranjeros.

Durante el estudio y resolución de estos casos se constató la violación de derechos tales como los derechos del niño, la libertad de expresión, el principio de legalidad, la prohibición de expulsión de nacionales, el derecho a ser oído en un plazo razonable, a la libertad personal, a la protección y a las garantías judiciales, a la vida, a no ser sometido a detención arbitraria, a la integridad y libertad personales, a la protección y honra de la dignidad, a la identidad, a la nacionalidad, al nombre, a la residencia y circulación, y a no ser objeto de injerencias arbitrarias.

Ante el menoscabo de estos derechos, la Corte IDH ha ordenado medidas de reparación tales como la eliminación de antecedentes penales, la publicación de sentencias, la obligación de proveer un recurso efectivo, la adopción de medidas administrativas, el reintegro al cargo, la no imposición de la pena de muerte, la formación en DDHH, la restitución del vínculo familiar, la práctica de tratamientos psicológicos, el dejar sin efecto sentencias, medidas y normas $\mathrm{y}$-con una alta frecuencia- la adecuación del derecho interno ${ }^{79}$.

Por consiguiente, la jurisprudencia de la Corte IDH revela la existencia de victimizaciones que no involucran conflictos armados, dictaduras o amenazas

78 La siguiente afirmación se basa en el análisis de las siguientes sentencias: Corte IDH. Caso Kimel vs. Argentina. Fondo, Reparaciones y Costas. Sentencia del 2 de mayo de 2008. Serie C No. 177; Corte IDH. Caso Yvon Neptune vs. Haití. Fondo, Reparaciones y Costas. Sentencia del 6 de mayo de 2008. Serie C No. 180; Corte IDH. Caso Apitz Barbera y otros ("Corte Primera de lo Contencioso Administrativo") vs. Venezuela. Excepción Preliminar, Fondo, Reparaciones y Costas. Sentencia del 5 de agosto de 2008. Serie C No. 182; Corte IDH. Caso Castañeda Gutman vs. México. Excepciones Preliminares, Fondo, Reparaciones y Costas. Sentencia del 6 de agosto de 2008. Serie C No. 184; Corte IDH. Caso DaCosta Cadogan vs. Barbados. Excepciones Preliminares, Fondo, Reparaciones y Costas. Sentencia del 24 de septiembre de 2009. Serie C No. 204; Corte IDH. Caso Barreto Leiva vs. Venezuela. Fondo, Reparaciones y Costas. Sentencia del 17 de noviembre de 2009. Serie C No. 206; Corte IDH. Caso Fornerón e hija vs. Argentina. Fondo, Reparaciones y Costas. Sentencia del 27 de abril de 2012. Serie C No. 242; Corte IDH. Caso Artavia Murillo y otros (Fecundación in vitro) vs. Costa Rica. Excepciones Preliminares, Fondo, Reparaciones y Costas. Sentencia del 28 de noviembre de 2012. Serie C No. 257; Corte IDH. Caso de Personas dominicanas y haitianas expulsadas vs. República Dominicana. Excepciones Preliminares, Fondo, Reparaciones y Costas. Sentencia del 28 de agosto de 2014. Serie C No. 282.

79 El análisis pormenorizado de estas sentencias, las cuales se ocupan de casos en contextos no transicionales, hace parte de la investigación, desarrollada por la autora como doctoranda de la Universidad de Medellín, titulada "El derecho a la reparación de víctimas como garantía de justicia”. 
terroristas, pues las mismas surgen de la violencia sistémica, propia de cada sociedad, en contextos no transicionales. Lo anterior señala la necesidad, contextualizada teórica, jurídica y socialmente, de reconocer el derecho a la reparación como un derecho humano, al entenderse la vulnerabilidad como una situación que puede darse en circunstancias que están fuera del marco de la $\mathrm{JT}^{80}$.

\section{CONCLUSIONES}

Un gran conjunto de investigaciones sobre reparación se ha orientado, hasta el momento, hacia la indagación de los orígenes y las causas de los conflictos armados, las dictaduras o los regímenes autoritarios, para justificar la necesidad de reparar a las personas que fueron víctimas en tales situaciones. Se ha estudiado, igualmente, el potencial de la reparación para superar situaciones que generan violaciones de los DDHH e infracciones al DIH. Por consiguiente, la naturaleza de la reparación varía según el contexto de aplicación y el referente de elaboración conceptual, los cuales pueden ser evidenciados en cada área del conocimiento.

Además, se han señalado, en este texto, una serie de perspectivas que muestran una falsa diversidad en el estudio del derecho a la reparación. A pesar de la multidisciplinariedad de las intervenciones académicas (que van de lo jurídico a lo filosófico, pasando por el aporte de las políticas públicas, la sociología y la historia), se revela una endogamia epistemológica, relacionada directamente con la omnipresencia del marco de la JT. Lo que sugiere esto es que la transicionalidad, a pesar de ser planteada en términos de evolución histórica, implica una limitación del derecho a la reparación, un enclaustramiento, un rechazo a su capacidad para exigirle al Estado de derecho un compromiso permanente con la sociedad civil.

El análisis de estas circunstancias revela un confinamiento de la categoría de reparación en los contextos de la JT: dicho confinamiento limita la eficacia de la categoría mencionada. La consecuencia del confinamiento es que convierte la reparación, que es un derecho fundamental de todas las personas que han sido víctimas de violaciones de sus DDHH, en un instrumento al servicio de fines políticos y sociales, durante una etapa de transicionalidad. Por consiguiente, el cumplimiento de finalidades políticas limita la fortaleza y el alcance de la categoría de la reparación para ser aplicada en contextos no transicionales.

80 La mención de estas sentencias y su contribución al reconocimiento eficaz del derecho a la reparación confirma que la Corte IDH, durante más de 30 años, ha sido pionera en establecer una serie de decisiones que pueden influir positivamente tanto en el bienestar de las personas como en la dimensión jurídica latinoamericana. Véase NASH RoJAs, C. Las reparaciones ante la Corte Interamericana de Derechos Humanos (1988-2007). Santiago de Chile: Universidad de Chile, 2009, 85. 
Aunque la JT pueda tener una utilidad innegable en el corto y el mediano plazo, dada su esencia y utilidad para la reconstrucción de la sociedad civil, no puede servir para limitar el que las víctimas sean reconocidas como tales, una vez que se hayan superado formalmente situaciones como conflictos armados, dictaduras o regímenes autoritarios.

Es momento, entonces, de proponer, como se hace en el presente texto, un nuevo marco de referencia para el estudio de la reparación basado en la teoría de los DDHH, para que sea consistente con su naturaleza como derecho de todas las personas. Este marco debe formularse con independencia de los referentes de elaboración conceptual y de los contextos de aplicación en los que se han enfocado, con monótona persistencia, un grupo considerable de investigaciones realizadas hasta ahora.

\section{REFERENCIAS}

Aïssaoui, K. La victime d'infraction pénale de la réparation à la restauration. Lyon: Université Jean Moulin, Lyon III, 2013.

Balaguer Soriano, A. La semilla sembrada: el potencial transformador de la Justicia Transicional y la restitución de tierras a mujeres en Colombia. Valencia: Universidad de Valencia, 2015.

Barbuto, V. et al. Las víctimas y la Justicia Transicional. ¿Están cumpliendo los Estados latinoamericanos con los estándares internacionales? Washington D.C.: Fundación para el Debido Proceso Legal, 2010.

Benavides Vanegas, F. S. La verdad, las confesiones judiciales y la memoria del conflicto en el proceso de Justicia Transicional en Colombia. Barcelona: Universitat Pompeu Fabra, 2015.

Benavides Vanegas, F. S. ¿Tiene futuro la Justicia Transicional? En Revista Internacional Derecho Penal Colombiano. N. ${ }^{\circ}$ 58, 2017, 5-44.

Bloomfield, D., Barnes, T. y Huyse, L. (eds.). Reconciliation after Violent Conflict. A Handbook. Stockholm: Holmberg \& Holmberg Design АВ e International Institute for Democracy and Electoral Assistance - IDEA, 2003.

Calderón Gamboa, J. F. La evolución de la "reparación integral" en la jurisprudencia de la Corte Interamericana de Derechos Humanos. México, D.F.: Comisión Nacional de los Derechos Humanos, 2013.

CAMILleri, M. Justicia y paz en Colombia: el derecho a la verdad, la justicia y la reparación. Análisis de la Ley 975 y Decreto 4760 de 2005 según estándares internacionales de protección de los derechos humanos. San José de Costa Rica: Centro por la Justicia y el Derecho Internacional - Cejil, 2006.

Contreras Ramírez, J. L. La responsabilidad civil como reparación a las víctimas de graves violaciones a los derechos humanos en el marco de la jurisdicción universal. Getafe: Universidad Carlos III de Madrid, 2015. 
CORREA, C. et al. Reparación integradora para niños, niñas y jóvenes víctimas de reclutamiento ilícito en Colombia. Bogotá: Centro Internacional para la Justicia Internacional, 2014.

De Greiff, P. (ed.). The Handbook of Reparations. New York: The International Center for Transitional Justice y Oxford University Press, 2010.

Delgado Barón, M. Las víctimas como sujetos políticos en el proceso de Justicia y Paz en Colombia: discursos imperantes y disruptivos en torno a la reconciliación, la verdad, la justicia y la reparación. México, D.F.: Flacso México, 2011.

Elster, J. Rendición de cuenta: la Justicia Transicional en perspectiva histórica. Buenos Aires: Katz, 2006

Evans, C. The Right to Reparation in International Law for Victims of Armed Conflict. London: Cambridge University Press, 2012.

Fries, L. (coord.). Sin tregua. Políticas de reparación para mujeres víctimas de violencia sexual durante dictaduras y conflictos. Santiago de Chile: Corporación Humanas y Centro Regional de Derechos Humanos y Justicia de Género, 2008.

Garavito Rodríguez, C. y Lam, Y. Etnorreparaciones: la justicia étnica colectiva y la reparación. Oslo: Torkel Opsahl Academic Epublisher y Peace Research Institute Oslo - PRIO, 2012.

GARCía RAMíREz, S. Raíz, actualidad y perspectivas de la jurisdicción interamericana de derechos humanos. México, D.F.: Cuestiones Constitucionales, 2009.

Gómez Dupuis, N. Víctimas sobrevivientes de masacres: daño psicosocial y estrategias de reparación. San José de Costa Rica: Instituto Interamericano de Derechos Humanos, 2004.

González González, D. Y., Amaya Barrera, N. G. y Cárdenas Ortiz, F. Justicia restaurativa frente a la Ley de Justicia y Paz y la Ley de Víctimas en Colombia. Bogotá: Universidad Libre, 2012.

GonzÁlez Joves, A. Alcances y limitaciones de la Ley de Justicia y Paz de Colombia (Ley 975 de 2005) como construcción de paz. Granada: Universidad de Granada, 2012.

GuILIs, G. La reparación: acto jurídico y simbólico. San José de Costa Rica: Equipo Interdisciplinario del Departamento de Entidades de la Sociedad Civil del Instituto Interamericano de Derechos Humanos, 2004.

Guillerot, J. y Magarell, L. Reparaciones en la transición peruana. Memorias de un proceso inacabado. New York: Asociación Pro Derechos Humanos - APRodeH, International Center for Transitional Justice - ICTJ y OXFAM, 2006.

Hazan, P. Measuring the Impact of Punishment and Forgiveness: A Framework for Evaluating Transitional Justice. Geneva: Cambridge University Press e International Committee of the Red Cross (ICRC), 2006.

JeLin, E. La lucha por el pasado: cómo construimos la memoria social. Buenos Aires: Siglo XXI Editores, 2017. 
Juliao Vargas, C. S. Desplazamiento interno, verdad, justicia y reparación en Colombia: la percepción de las integrantes de la Asociación Yo Mujer. Granada: Universidad de Granada y Programa "Paz, Conflictos y Democracia", 2013.

Laplante, L. J. The plural justice aims of reparations. En Buckley-Zistel, S., Koloma Beck, T., Braun, C. y Mieth, F. (eds.), Transitional Justice Theories. New York: Routledge, 2014.

López ZwaIG, E. S. Reparaciones para mujeres sobrevivientes de violencia sexual durante conflictos armados y dictaduras. Los casos de Argentina y Colombia. Bogotá: Universidad de los Andes, 2016.

Mani, R. La reparación como un componente de la Justicia Transicional: la búsqueda de la "justicia reparadora" en el posconflicto. En Minow, M., Crocker D. A. y MANI, R. (coords.), Justicia Transicional. Bogotá: Siglo del Hombre Editores, Pontificia Universidad Javeriana - Instituto Pensar y Universidad de los Andes, 2011.

Mendoza Molina, M. Reparación para las víctimas en el Municipio de Tumaco. En Revista Análisis Político. N. ${ }^{\circ}$ 90, 2017.

Meredith, V. M. Victim Identity and Respect for Human Dignity: A Terminological Analysis. Geneva: Cambridge University Press e International Committee of the Red Cross - ICRC, 2009.

Moreno, M. C. (ed.). Políticas públicas que hacen justicia: cuatro temas en la agenda de reparación en Colombia. Bogotá: Centro Internacional para la Justicia Transicional y Programa de las Naciones Unidas para el Desarrollo - PNUd, 2011.

Nash Rojas, C. Las reparaciones ante la Corte Interamericana de Derechos Humanos (1988-2007). Santiago de Chile: Universidad de Chile, 2009.

Pacheco Oreamuno, G., Acevedo Narea, L. y Galli, G. Verdad, justicia y reparación. Desafíos para la democracia y la convivencia social. San José de Costa Rica: Instituto Internacional para la Democracia y la Asistencia Electoral, Instituto Interamericano para los Derechos Humanos y Agencia Sueca de Cooperación Internacional para el Desarrollo, 2005.

PAGE, J. M. Reparations and State Accountability. Harvard University, 2015.

Quinche RamíRez, M. F. Los estándares de la Corte Interamericana y la Ley de Justicia y Paz. Bogotá: Universidad del Rosario y Universidad de Buenos Aires, 2009.

RettBerg, A. Reparación en Colombia. ¿Qué quieren las víctimas? Bogotá: Deutsche Gesellschaft für Technische Zusammenarbeit (GTZ) GmbH, Embajada de la República de Alemania, Fiscalía General de la Nación y Universidad de los Andes, 2008.

Rollim Peixoto, A. La evolución del sistema de reparación a las víctimas de tortura en el ámbito de la Corte Interamericana de Derechos Humanos. Salamanca: Universidad de Salamanca, 2015.

Salcedo López, D. M. Género, derecho de las víctimas y Justicia Transicional: retos en Colombia. Granada: Universidad de Granada, 2013. 
Socha Masso, N. La reparación integral: los derechos de las víctimas y las obligaciones del Estado. Bogotá: Defensoría del Pueblo y Cooperación Técnica Alemana - GIZ, 2013.

Stan, L. y Nedelsky, N. (eds.). Encyclopedia of Transitional Justice. Vol. 1. New York: Cambridge University Press, 2013.

Teitel, R. Transitional Justice Genealogy. En Harvard Human Rights Journal. Vol. 16, 2003.

Theidon, K. Género en transición: sentido común, mujeres y guerra. Bogotá: Instituto de Estudios Políticos y Relaciones Internacionales - IEPRI, Universidad Nacional de Colombia, 2007.

Turner, C. Deconstructing Transitional Justice. En Law \& Critique. Vol. 24 (2), 2013, 193-209.

Ulfe Young, M. E. ¿Y después de la violencia que queda? Víctimas, ciudadanos y reparaciones en el contexto post-CVR en el Perú. Buenos Aires: Consejo Latinoamericano de Ciencias Sociales - CLACSO, 2013.

VACAS Fernández, F. Los derechos de las víctimas y la negociación: el caso de Colombia. En Díaz-Barrado, C. M., Fernández Liesa, C. R. y Rodríguez-Villasante y Prieto, J. L. (eds.), Derecho internacional humanitario y derechos humanos. Reflexiones sobre el conflicto colombiano. Pamplona y Cizur Menor: Civitas Thomson Reuters e Instituto Universitario de Estudios Internacionales y Europeos "Francisco de Vitoria" - Universidad Carlos III de Madrid, 2013.

VAllès Muñío, D. Les reparacions econòmiques pels danys derivats de la Guerra Civil Espanyola. Barcelona: Universitat Pompeu Fabra, 2012.

Vandeginste, S. Reparation. En Bloomfield, D., Barnes, T. y Huyse, L. (eds.), Reconciliation after Violent Conflict. A Handbook. Stockholm: Holmberg \& Holmberg Design AB e International Institute for Democracy and Electoral Assistance - IDEA, 2003.

ŽıžEK, S. Sobre la violencia: seis reflexiones marginales. Barcelona, Paidós.

\section{Material en línea}

Bello, M. N., Salcedo G., J. C. y Alvarado, L. L. La reparación administrativa a las víctimas de la violencia en Colombia: análisis del Decreto 1290 del 2008. 2012. [En línea]. Disponible en: http://www.bivipas.unal.edu.co/bitstream/10720/594/1/L-140PIUPC-2012-460.pdf (Consultado el 30 de octubre de 2018).

Centro Internacional de Toledo para la Paz - citpax. Tercer Informe del Observatorio Internacional para el Desarme, la Desmovilización y la Reintegración (DDR) según el marco jurídico de la Ley de Justicia y Paz. 2010. [En línea]. Disponible en: http://www. toledopax.org/sites/default/files/Tercer_Informe_CITpax_Observatorio_DDR_Ley_Justicia_Paz_septiembre_2010.pdf (Consultado el 27 de septiembre de 2018).

Organización de los Estados Americanos, Comisión Interamericana de Derechos Humanos. Lineamientos principales para una Política Integral de Reparaciones. Washington, D.C.: Secretaría General de la Organización de los Estados Americanos, 2008. [En línea]. Disponible en: http://www.cidh.org/pdf\%20files/Lineamientos\%20 
principales\%20para\%20una\%20pol\%C3\%ADtica\%20integral\%20de\%20reparaciones. pdf (Consultado el 27 de septiembre de 2018).

Gómez Isa, F. Las víctimas y su derecho a la reparación. 2006. [En línea]. Disponible en: http://www.fuhem.es/media/ecosocial/file/revista-papeles/93/arts.\%20 93/V\%C3\%ADctimas_y_Derecho_reparaci\%C3\%B3n_93.pdf (Consultado el 27 de septiembre de 2018).

Gómez SÁnchez, G. S. Justicia Transicional "desde abajo”: un marco teórico constructivista crítico para el análisis de la experiencia colombiana. 2013. [En línea]. Disponible en: http://bibliotecadigital.udea.edu.co/bitstream/10495/3142/1/GomezGabriel_Justiciatransicionaldesdeabajo.pdf (Consultado el 30 de octubre de 2018).

Guerrero Andreu, P. A. De la responsabilidad del Estado chileno por acciones de Gobiernos de facto. Análisis histórico-crítico de las leyes de reparación. Universidad de Chile, 2008. [En línea]. Disponible en: http://repositorio.uchile.cl/tesis/uchile/2008/ de-guerrero_p/html/index-frames.html; www.cybertesis.uchile.cl/tesis/uchile/2008/ de-guerrero_p/pdfAmont/de-guerrero_p.pdf (Consultado el 27 de septiembre de 2018).

Kalmanovitz, P. 2010. Justicia correctiva vs. justicia social en casos de conflicto armado. 2010. [En línea]. Disponible: https://revistas.urosario.edu.co/index.php/sociojuridicos/ article/view/1366 (Consultado el 27 de septiembre de 2018).

Olásolo Alonso, H. Dignidad humana, derecho internacional penal y Justicia Transicional. 2014. [En línea]. Disponible: https://revistas.urosario.edu.co/index.php/sociojuridicos/ article/view/3218 (Consultado el 27 de septiembre de 2018).

Orentlicher, D. - Organización de las Naciones Unidas (onu). Conjunto de principios actualizado para la protección y la promoción de los derechos humanos mediante la lucha contra la impunidad. 2005. [En línea]. Disponible en: http://www.Derechos.org/ nizkor/impu/impuppos.html (Consultado del 30 de octubre de 2018).

Organización de las Naciones Unidas (onu). Principios y directrices básicos sobre el derecho de las víctimas de violaciones manifiestas de las normas internacionales de derechos humanos y de violaciones graves del derecho internacional humanitario a interponer recursos y obtener reparaciones. 2005. [En línea]. Disponible: https:// www.ohchr.org/sp/professionalinterest/pages/remedyandreparation.aspx. (Consultado el 27 de septiembre de 2018).

Organización de las Naciones Unidas (onu), Alto Comisionado para los Derechos Humanos. Justicia Transicional y derechos económicos, sociales y culturales. 2014. [En línea]. Disponible en: http://www.ohchr.org/Documents/Publications/HR-PUB-13-05_sp.pdf (Consultado el 27 de septiembre de 2018).

Pele, A. La dignidad humana: modelo contemporáneo y modelos tradicionales / A dignidade humana: modelo contemporaneo e modelos tradicionais. 2015. [En línea]. Disponible en: https://seer.imed.edu.br/index.php/revistadedireito/rt/printerFriendly/892/944 (Consultado el 27 de septiembre de 2018). 
PIPER ShAFIR, I. Obstinaciones de la memoria: la dictadura militar chilena en las tramas del recuerdo. 2006. [En línea]. Disponible en: https://www.tdx.cat/handle/10803/5444\#page=1 (Consultado el 27 de septiembre de 2018).

Uprimny YePes, R. y GuZmán RodríGuez, D. E. En búsqueda de un concepto transformador y participativo para las reparaciones en contextos transicionales. 2010. [En línea]. Disponible en: http://www.deJusticia.org/files/r2_actividades_recursos/fi_name_recurso.679.pdf (Consultado el 27 de septiembre de 2018)

VAN Boven, T. Estudio relativo al derecho a la restitución, indemnización y rehabilitación a las víctimas de violaciones flagrantes de los derechos humanos y las libertades fundamentales. 1993. [En línea]. Disponible en: http://www.derechos.org/nizkor/ espana/doc/boven.html

Waldron, J. J. Is Dignity the Foundation of Human Rights? 2013. [En línea]. Disponible en: https://www.peacepalacelibrary.nl/ebooks/files/36335655X.pdf (Consultado el 27 de septiembre de 2018).

\section{Jurisprudencia de la Corte Interamericana de Derechos Humanos (Corte IDH)}

Corte IDH. Caso Kimel vs. Argentina. Fondo, Reparaciones y Costas. Sentencia del 2 de mayo de 2008. Serie C No. 177.

Corte IDH. Caso Yvon Neptune vs. Haití. Fondo, Reparaciones y Costas. Sentencia del 6 de mayo de 2008. Serie C No. 180.

Corte IDH. Caso Apitz Barbera y otros ("Corte Primera de lo Contencioso Administrativo") vs. Venezuela. Excepción Preliminar, Fondo, Reparaciones y Costas. Sentencia del 5 de agosto de 2008. Serie C No. 182.

Corte idh. Caso Castañeda Gutman vs. México. Excepciones Preliminares, Fondo, Reparaciones y Costas. Sentencia del 6 de agosto de 2008. Serie C No. 184.

Corte IDH. Caso DaCosta Cadogan vs. Barbados. Excepciones Preliminares, Fondo, Reparaciones y Costas. Sentencia del 24 de septiembre de 2009. Serie C No. 204.

Corte IDH. Caso Barreto Leiva vs. Venezuela. Fondo, Reparaciones y Costas. Sentencia del 17 de noviembre de 2009. Serie C No. 206.

Corte IDH. Caso Fornerón e hija vs. Argentina. Fondo, Reparaciones y Costas. Sentencia del 27 de abril de 2012. Serie C No. 242.

Corte IDH. Caso Artavia Murillo y otros (Fecundación in vitro) vs. Costa Rica. Excepciones Preliminares, Fondo, Reparaciones y Costas. Sentencia del 28 de noviembre de 2012. Serie C No. 257.

Corte IDH. Caso de Personas dominicanas y haitianas expulsadas vs. República Dominicana. Excepciones Preliminares, Fondo, Reparaciones y Costas. Sentencia del 28 de agosto de 2014. Serie C No. 282. 